\title{
EFEKTIFITAS MODEL PEMBELAJARAN ROLE PLAYING PADA MATA KULIAH PENDIDIKAN KEWARGANEGARAAN
}

\author{
Yunita Dwi Pristiani \\ Universitas Nusantara PGRI Kediri \\ Email : yunitadp@unpkediri.ac.id
}

Naskah diterima: 11/10/2018 revisi: 31/10/2018 disetujui: 31/10/2018

\begin{abstract}
Abstrak
Tujuan penelitian ini bertujuan mengetahui gambaran obyektif efektifitas pembelajaran Role Playing pada mata kuliah kewarganegaraan. Obyek penelitian ini adalah mahasiswa Tingkat III Program Studi PPKN Universitas Nusantara PGRI Kediri. Penelitian ini merupakan Penelitian Tindakan Kelas dengan jenis deskriptif kualitatif. Penelitian dilakukan dalam dua siklus, siklus pertama menunjukkan hasil pemahaman mahasiswa masih kurang maksimal, yaitu dengan nilai rata-rata pemahaman yang diperoleh adalah 66.7 poin dengan prosentase rata-rata antusias mahasiswa dalam pembelajaran PKn adalah 35\%. Siklus ke-2 menunjukkan peningkatan hasil, yaitu meningkatnya pemahaman mahasiswa pada materi Pendidikan Kewarganegaraan dengan perolehan nilai rata-rata 84.0 poin dengan prosentase rata-rata antusias mahasiswa dalam pembelajaran PKn adalah $60 \%$. Diskusi hasil Role Playing yang dilakukan menggambarkan tingkat pemahaman dan antusias mahasiswa menjadi lebih baik. Sehingga hasil penelitian dapat disimpulkan bahwa pembelajaran menggunakan strategi Role Playing efektif untk dilakukan pada mata kuliah Kewarganegaraan.
\end{abstract}

Kata kunci: Efektifas, Role Playing, PKn

\section{THE EFFECTIVENESS OF LEARNING ROLE PLAY MODEL IN CITIZENSHIP EDUCATION COURSE}

\begin{abstract}
The purpose of this study aims to determine the objective picture of the effectiveness of Role Playing learning in citizenship courses. The object of this research was Level III students at the University of Nusantara PPKN Study Program PGRI Kediri. This research is a Class Action Research with qualitative descriptive type. The study was conducted in two cycles, the first cycle showed the results of student understanding were still not maximal, with the average value of understanding obtained was 66.7 points with the average percentage of student enthusiasm in Civics learning was 35\%. The second cycle shows an increase in results, namely an increase in student understanding of Citizenship Education material with the acquisition of an average value of 84.0 points with the average percentage of student enthusiasm in Civics learning is 60\%. The Role Playing discussion conducted illustrates the students' level of understanding and enthusiasm for the better. So that the results of the study can be concluded that learning using Role Playing strategies is effective for the Citizenship course.
\end{abstract}

Keywords: Effective, Role Playing, PKn 


\section{PENDAHULUAN}

Mahasiswa adalah tokoh yang akan ikut memberi kontribusi besar dalam penyiapan generasi emas 2045 mendatang. Menurut Amm (2018) dalam tulisannya di salah satu portal online menyebutkan, bahwa generasi emas adalah generasi yang diharapkan mampu menjadi perintis adanya perubahan dalam menciptakan kehidupan dan peradaban bangsa yang lebih maju. generasi emas yang dicita-citakan ini merupakan generasi yang memiliki kecerdasan komprehensif, yakni generasi yang produktif, inovatif, mampu melakukan interaksi sosial yang baik, dan berperadaban unggul. Sehingga, Mahasiswa yang hari ini memasuki kampus-kampus di berbagai jurusan, dikemudian hari akan bertanggungjawab mengamalkan ilmu yang mereka dapatkan, baik kepada anak-anak mereka, anak didik di sekolah maupun sekedar bekal untuk mereka menjalankan hidup sehari-hari dilingkungan kerja maupun publik. Oleh karena itu Pendidikan Kewarganegaraan (PKn) menjadi sangat penting untuk dijiwai oleh tiap-tiap mahasiswa. PKn secara perlahan namun pasti akan menumbuhkan rasa cinta tanah air pada diri mahasiswa, sehingga mahasiswa akan memahami dengan baik hak dan kewajiban sebagai warga negara, termasuk mendedikasikan seluruh ilmu yang mereka miliki untuk kepentingan bangsa dan negara. akan tetapi, metode pengajaran PKn yang masih banyak ditemukan menggunakan metode-metode lama, seperti ceramah, diskusi, atau meminta mahasiswa me-resume materi dan lainnya yang membuat antusias mahasiswa terhadap PKn rendah, sehingga pemahaman dan penjiwaan mahasiswa terhadap materi PKn juga sangat minimal. Berdasarkan observasi yang dilakukan peneliti dengan beberapa dosen mata kuliah PKn, pembelajaran mayoritas menggunakan metode ceramah,. Hasil observasi tersebut menunjukkan, metode tersebut membuat mahasiswa cenderung pasif, tidak tampak mahasiswa yang antusias mengutarakan pendapat atau memberi pertanyaan maupun pernyataan kepada dosen. Kelas terkesan sangat kaku dan tegang, sehingga mahasiswa enggan memberikan pertanyaan pada dosen. Tukar pendapat diantara mahasiswa sendiri juga tidak terjadi, hal ini dikarenakan dalam metode ceramah sangat kecil kemungkinan dosen memberikan kesempatan kepada mahasiswa untuk menganalisis permasalahan (hal-hal kasuistik) yang dapat mengembangkan imajinasi mahasiswa dan dapat dijadikan bahan diskusi antara mahasiswa dengan mahasiswa maupun antara mahasiswa dengan dosen. Hal inilah yang mendorong penulis untuk mencoba melakukan penelitian tindakan kelas menggunakan strategi pembelajaran -Role Playing dengan materi demokrasi sebagai salah satu materi yang terdapat dalam mata kuliah PKn.

Permasalahan dalam penelitian ini adalah bagaimana tingkat pemahaman mahasiswa terhadap materi yang diberikan dalam mata kuliah PKn ketika diajarkan dengan strategi pembelajaran Role Playing. Dan apakah strategi belajar Role Playing merupakan strategi yang efektif digunakan dalam pembelajaran $\mathrm{PKn}$ di Perguruan tinggi. Role Playing atau disebut juga sosiodrama, Adam Blatner, M.D, 2009, mengatakan Role Playing is a derivative of sociodrama, is a method of exploring the issues involved in complex social situations. Role play memungkinkan mahasiswa untuk terlibat secara langsung dalam materi atau permasalahan yang dibahas dengan cara mendramatisasikan tingkah laku yang berkaitan dengan masalah sosial.

Pada dasarnya role play adalah strategi yang simple, karena lebih fokus pada materi yang dibahas, lebih objektif, jelas dan mudah dimengerti. Metode bermain peran sebenarnya adalah untuk mengkreasikan suatu kejadian yang telah atau mungkin terjadi di masa lalu, sekarang dan masa mendatang (Syaiful Djamarah dan Aswan Zain,1996). Dengan demikian mahasiswa lebih menjiwai peran tersebut ketika di hadapkan langsung dalam kehidupan sehari-hari. Menurut Oemar 
Hamalik (2001), tujuan dari metode pembelajaram disesuaikan dengan jenis belajar, antara lain adalah a) Belajar dengan berbuat, dan b) Belajar melalui peniruan (imitasi). Belajar dengan berbuat artinya, para mahasiswa melakukan peran tertentu sesuai dengan kenyataan yang sebenarnya, tujuannya yaitu mengembangkan keterampilan-keterampilan interaktif maupun reaktif.

Tujuan dari penelitian ini adalah menguji metode yang efektif dalam pembelajaran PKn di perguruan Tinggi, agar pemahaman mahasiswa dalam mata kuliah PKn meningkat. Dengan demikian, dengan ilmu dan keahlian masing-masing, mahasiswa sebagai agen perubahan benarbenar mampu memberikan manfaat bagi bangsa dan negara. Penelitian tentang strategi pembelajaran Role Playing yang pernah dilakukan sebelumnya dengan judul "Upaya Meningkatkan Nilai-Nilai Karakter Peserta Didik Melalui Penerapan Metode Role Playing" oleh Kiromim Baroroh (2011) adalah membahas soal implementasi Role Playing dalam meningkatkan nilai-nilai karakter mahasiswa pada mata kuliah ekonomi kerakyatan. Perbedaan dengan penelitan ini adalah, dPenelitian tersebut menggunakan indikator disiplin, kerja keras dan kreatifitas untuk menguji metode Role Playing, sedangkan penelitian ini menggunakan indicator Tingkat pemahaman dan antusias belajar mahasiswa untuk menguji strategi pembelajaran Role Playing.

\section{METODE}

\section{Jenis Penelitian}

Penelitian ini menggunakan Penelitian Tindakan Kelas. Kelas dalam penelitian ini tidak terbatas dalam koridor ruang dan waktu, akan tetapi lebih bebas dan luas sesuai kebutuhan yang diperlukan untuk proses pemahaman materi yang lebih mendalam

\section{Waktu dan Tempat Penelitian}

Penelitian ini telah dilaksanakan pada semester ganjil, Bulan Maret 2017.

Target/Subjek Penelitian
Objek penelitian ini adalah mahasiswa tingkat III Program Studi Pendidikan Pancasila dan Kewarganegaraan, Universitas Nusantara PGRI Kediri yang berjumlah 14 mahasiswa, dan seorang dosen sebagai peneliti sekaligus pelaku tindakan.

\section{Prosedur}

Mengenai prosedur penelitian yang digunakan dalam penelitian ini yakni meliputi: (a) perencanaan, (b) pelaksanaan, (c) observasi dan (d) refleksi. Pada setiap siklusnya menerapkan model pembelajaran Role Playing sesuai dengan prosedur yang dikemukakan oleh Hamzah B Uno (2009) antara lain : a). pemanasan, b) memilih partisipan, c) menyiapkan pengamat, d) menata panggung, e) memainkan peran, f) diskusi dan evaluasi, g) memainkan ulang peran, h) melakukan diskusi dan evaluasi, i) berbagi pengalaman dan kesimpulan.

\section{Data, Intrumen, dan Teknik Pengumpulan Data}

Teknik pengumpulan data yang dilakukan dalam penelitian ini adalah dengan observasi, dan dokumentasi. Strategi pembelajaran yang digunakan dalam penelitian ini adalah strategi Role Playing. Role Playing merupakan cara yang paling baik untuk menggambarkan keterampilan inisiatif, komunikasi, pemecahan masalah, kesadaran diri, dan juga kerja sama dalam tim apabila dibandingkan dengan metode pembelajaran konvensional (Blatner.A, 2000).

Data yang diperoleh dalam penelitian ini adalah data kualitatif, menggunakan instrumen berupa lembar observasi. Analisis data dilakukan sesuai dengan masingmasing karakteristik data yang terkumpul, yaitu dengan cara deskriptif kualitatif. Bentuk Role Playing dalam penelitian ini yaitu mahasiswa bermain peran dengan membuat film pendek bertema "Realita Demokrasi Kontemporer Indonesia", setelah sebelumnya menerima materi demokrasi di dalam kelas. Indikator ketercapaian tindakan ini adalah, pengukuran data dilakukan dengan cara mengamati tingkat pemahaman mahasiswa terhadap materi demokrasi 
sebelum dilakukan Role Playing dan setelah dilakukan Role Playing. Pengukuran hasil dilakukan melalui diskusi, dalam diskusi peneliti akan mengamati tingkat keaktifan dan antusias mahasiswa dalam menyampaikan pendapatnya masingmasing.

\section{Teknik Analisis Data}

Mengenai analisis data pada penelitian ini dilakukan secara deskriptf kualitatif, baik untuk data kualitatif maupun kuantitatif.

\section{HASIL DAN PEMBAHASAN}

Tujuan penggunaan metode Role Playing adalah agar mahasiswa lebih memahami materi yang diberikan. Dengan bermain peran mahasiswa tentu akan lebih menjiwai materi yang dibahas. Syaiful Bahri Djamarah dan Aswan Zain (1996) menyampaikan, tujuan penggunaan metode sosio drama (Role Playing) antara lain adalah : (1) Agar mahasiswa dapat menghayati dan menghargai perasaan orang lain, (2) Agar mahasiswa dapat membagi tanggung jawab, (2) Agar mahasiswa belajar bagaimana mengambil keputusan secara spontan, (3) Dan merangsang kelas untuk berfikir kreatif memecahkan masalah.

Penelitian ini dilakukan dalam 2 siklus. Tindakan yang dilakukan pada siklus I antara lain sebagai berikut : (1) Pemanasan atau Brain Storming, (2) Dosen mengamati Jawaban Mahasiswa, (3) Menjelaskan materi Demokrasi dalam mata kuliah Pendidikan Kewarganegaraan, Menjelaskan Metode Role Playing, (5) Menyusun Skenario, (6) Meminta mahasiswa untuk mendiskusikan peran, (7) Mahasiswa memperagakan peran sesuai skenario di depan kelas, (8) Memberikan Test pertama

Pada tes pertama peneliti memberikan pertanyaan dalam bentuk essay kepada mahasiswa. Soal essay berjumlah 5 soal, dengan bobot kriteria nilai maksimal setiap soal adalah 20 poin. Setiap jawaban yang dituliskan mahasiswa diamati dengan seksama, untuk menentukan pencapaian kriteria jawaban benar yang sudah ditentukan. Dari pengamatan jawabanjawaban yang diberikan mahasiswa baik dalam kegiatan brain storming maupun pretest peneliti memperoleh nilai awal sebagai berikut pada tabel 1 .

\begin{tabular}{|r|l|c|c|c|c|}
\hline \multirow{2}{*}{ No } & \multicolumn{2}{|c|}{ Nama } & \multicolumn{2}{c|}{ Hasil Pemahaman } & \multicolumn{2}{c|}{ Tingkat Antusias } \\
\cline { 3 - 6 } & & Siklus I & Siklus II & Siklus I & Siklus II \\
\hline 1 & Tenggangrasa Agus Setiya & 62 & - & $10 \%$ & - \\
\hline 2 & Lia Setiawati & 70 & - & $40 \%$ & - \\
\hline 3 & Avila Maria Dhone Dara & 63 & - & $20 \%$ & - \\
\hline 4 & Awing Safira Haunanda & 60 & - & $40 \%$ & - \\
\hline 5 & Fitria Evitasari & 69 & - & $40 \%$ & - \\
\hline 6 & Ahmad Sidik & 65 & - & $20 \%$ & - \\
\hline 7 & Rangga Bangun Wardana & 65 & - & $40 \%$ & - \\
\hline 8 & Widia Anastasya & 67 & - & $30 \%$ & - \\
\hline 9 & Mufti Ezha Kumala & 69 & & $30 \%$ & - \\
\hline 10 & Fitria Roshida Nurhayati & 70 & - & $50 \%$ & - \\
\hline 11 & Susika Candra Oktavia & 68 & - & $30 \%$ & - \\
\hline 12 & Rizhal Nugraha & 70 & - & $50 \%$ & - \\
\hline 13 & Maria Bernadeta Refwalu & 67 & - & $30 \%$ & - \\
\hline 14 & Safiq Farisi Sayoga & 70 & - & $60 \%$ & - \\
\hline
\end{tabular}

121 | Yunita Dwi Pristiani, Efektifitas model pembelajaran role playing... 
nilai angka (\%) yang diperoleh mahasiswa di atas dinilai dari beberapa sering mahasiswa memberikan argumentasinya pada saat brain storming berlangsung. Dengan asumsi kriteria maksimal 10 kali berargumentasi adalah $100 \%$. Pada siklus I, mahasiswa masih terkendala pada penyusunan skenario, penghayatan mahasiswa terhadap skenario yang diperankan belum begitu baik, sehingga berpengaruh pada tingkat pemahaman dan keluasan pengetahuan yang diperoleh. pada siklus pertama mahasiswa belum banyak melakukan improvisasi pada saat sedang menjalankan perannya masing-masing.

Pada Siklus II peneliti melakukan langkah-langkah sebagai berikut : (1) Pemanasan atau Brain Storming, (2) Dosen mengamati Jawaban Mahasiswa, (3) Menjelaskan materi Demokrasi dalam mata kuliah Pendidikan Kewarganegaraan, (4) Menjelaskan Metode Role Playing, (5) Menyusun Skenario, (6) Meminta mahasiswa untuk mendiskusikan peran (7) Mahasiswa memperagakan peran sesuai skenario dan di dokumentasikan dalam bentuk Video, (8) Memberikan Tes ke-2

Model Role Playing yang dilakukan dalam siklus II dibuat dengan mendokumentasikannya dalam bentuk film pendek dengan tema "Realita Demokrasi Kotemporer Indonesia" dengan durasi 39 menit 47 detik yang menceritakan tentang proses pemilihan kepala Desa Sukamakmur dengan segala pernak-pernik wajah demokrasi di dalamnya. Setting tempat Role Playing juga lebih bervariasi dibandingkan dengan Role Playing pada siklus I. Pada siklus I Role Playing hanya dimainkan di depan kelas, sedangkan pada siklus II setting tempat lebih bervariasi, tidak hanya menggunakan ruang kelas tetapi juga beberapa tempat lainnya. Perubahan setting tempat ternyata menjadikan mahasiswa lebih kreatif dalam memainkan peran masing-masing. Terjadi banyak sekali improvisasi positif yang tidak tertulis dalam scenario. Pada Siklus II mahasiswa menjadi lebih memahami materi dibandingkan siklus I.

Diskusi Evaluasi dari Role Playing yang telah mereka suguhkan, didalamnya mengandung banyak peristiwa yang berkaitan dengan implementasi demokrasi yang sangat mungkin terjadi dalam kehidupan masyarakat sehari-hari. Antara lain misalnya Musyawarah, Money politic, Berperilaku jujur dan tidak jujur, kebijaksanaan, strategi, Pemecahan masalah, Penghasutan, Sportifitas dan lainnya.

Setelah diskusi dilakukan, evaluasi selanjutnya yang dilakukan adalah memberi soal essay kembali kepada mahasiswa dengan sejumlah 5 soal. Dari hasil diskusi dan jawaban yang diberikan mahasiswa dalam lembar kerja peneliti mendapatkan perbandingan nilai siklus I dan siklus II sebagai berikut pada tabel 2 :

Tabel 2. Nilai Hasil Siklus I dan 2

\begin{tabular}{|c|c|c|c|c|c|}
\hline \multirow{2}{*}{ No } & \multirow{2}{*}{ Nama } & \multicolumn{2}{|c|}{ Pemahaman } & \multicolumn{2}{|c|}{ Antusias } \\
\hline & & Siklus I & $\begin{array}{c}\text { Siklus } \\
\text { II }\end{array}$ & Siklus I & $\begin{array}{c}\text { Siklus } \\
\text { II }\end{array}$ \\
\hline 1 & Tenggangrasa Agus Setiya & 67 & 85 & $10 \%$ & $30 \%$ \\
\hline 2 & Lia Setiawati & 70 & 84 & $40 \%$ & $60 \%$ \\
\hline 3 & Avila Maria Dhone Dara & 63 & 68 & $20 \%$ & $40 \%$ \\
\hline 4 & Awing Safira Haunanda & 73 & 90 & $40 \%$ & $70 \%$ \\
\hline 5 & Fitria Evitasari & 75 & 95 & $40 \%$ & $70 \%$ \\
\hline 6 & Ahmad Sidik & 65 & 85 & $20 \%$ & $40 \%$ \\
\hline
\end{tabular}


Citizenship Jurnal Pancasila dan Kewarganegaraan Vol 6 No 2 Oktober 2018, hal 118-124

Avaliable online at : http://e-journal.unipma.ac.id/index.php/Citizenship

Print ISSN: 2302-433X Online ISSN : 2579-5740

\begin{tabular}{|r|l|c|c|c|c|}
7 & Rangga Bangun Wardana & 72 & 92 & $40 \%$ & $70 \%$ \\
\hline 8 & Widia Anastasya & 72 & 90 & $30 \%$ & $50 \%$ \\
\hline 9 & Mufti Ezha Kumala & 69 & 79 & $30 \%$ & $40 \%$ \\
\hline 10 & Fitria Roshida Nurhayati & 74 & 90 & $50 \%$ & $80 \%$ \\
\hline 11 & Susika Candra Oktavia & 68 & 84 & $30 \%$ & $40 \%$ \\
\hline 12 & Rizhal Nugraha & 75 & 89 & $50 \%$ & $90 \%$ \\
\hline 13 & Maria Bernadeta Refwalu & 67 & 84 & $30 \%$ & $70 \%$ \\
\hline 14 & Safiq Farisi Sayoga & 75 & 92 & $60 \%$ & $90 \%$ \\
\hline
\end{tabular}

Table di atas menunjukkan peningkatan yang sangat signifikan pada mahasiswa dalam memahami materi demokrasi. Tingkat kreatifitas mahasiswa juga meningkat baik. Hal ini dikarenakan dalam bermain peran (Role Playing), mahasiswa dituntut menjadi pribadi yang lebih imajinatif, mempunyai minat yang luas, mempunyai prakarsa, mampu berpikir mandiri, memiliki rasa ingin tahu yang tinggi, penuh energi dan percaya diri. Kreatif adalah orang yang memiliki kreatifitas, kratifitas adalah kemampuan seseorang untuk menghasilkan komposisi, produk, atau gagasan apa saja yang pada dasarnya baru, dan sebelumnya tidak dikenal pembuatnya (Elisabeth B. Hurlock, 2005). Dalam penelitian ini. disamping harus harus menjalankan peran sesuai dengan skenario, imajinasi dan intuisi masing-masing mahasiswa akan mempengarungi keluwesan dalam menjalankan peran. Dari sini kreatifitas mahasiswa dalam menghadapi lebih terasah, sehingga dikemudian hari alam kehidupan nyata mudah untuk menyelesaikan masalah.

\section{SIMPULAN DAN SARAN}

\section{Simpulan}

Hasil penelitian yang dilakukan telah berhasil menjawab permasalahan penelitian yang dibahas. Pertama, dari hasil nilai yang diperoleh, dapat disimpulkan bahwa metode Role Playing merupakan metode yang tepat untuk digunakan dalam pembelajaran mata kuliah PKn. Keefektifan penggunaan metode ini dibuktikan dengan 2 kriteria utama yang terpenuhi, antara lain yang pertama adalah meningkatnya pemahaman mahasiswa terhadap materi demokrasi pada mata kuliah Pendidikan Kewarganegaraan dibuktikan dengan nilai yang diperoleh dari hasil test pada siklus kedua yang mencapai nilai rata-rata 84.0 poin, meningkat dari nilai yang diperoleh pada siklus I dengan nilai rata-rata hanya pada angka 66.7 poin. Kedua, meningkatnya antusias mahasiswa dalam mengikuti diskusi materi, dibuktikan dengan prosentase nilai yang sebelumnya hanya $35 \%$ menjadi $60 \%$. Mahasiswa terlihat sangat bersemangat dalam menjalankan peran masing-masing dalam Role Playing, juga pada saat diskusi evaluasi berlangsung, mahasiswa lebih aktif berargumentasi dan melempar pertanyaan pada sesama teman maupun dosen. Sehingga dapat disimpulkan tujuan penelitian untuk mengetahui gambaran obyektif keefektifan metode Role Playing untuk digunakan sebagai strategi pembelajran Pendidikan Kewarganegaraan terpenuhi. bahwa strategi pembelajaran Role Playing merupakan strategi yang tepat untuk digunakan dalam pembelajaran Pendidikan Kewarganegaraan.

Saran yang dapat diberikan dari hasil penelitian ini adalah, supaya para pendidik, khususnya dosen yang mengampu mata kuliah Pendidikan Kewarganegaraan supaya lebih berinovasi dalam proses pembelajaran. Mencoba menggunakan metode-metode atau strategi-strategi pembelajaran baru untuk menggantikan metode lama seperti misalnya ceramah, diskusi atau me-resume dalam kegiatan belajar pembelajaran PKn.

\section{Saran}


Citizenship Jurnal Pancasila dan Kewarganegaraan Vol 6 No 2 Oktober 2018, hal 118-124

Avaliable online at : http://e-journal.unipma.ac.id/index.php/Citizenship

Print ISSN: 2302-433X Online ISSN : 2579-5740

Dari hasil penelitian ini maka peneliti memberikan saran pada dosen khususnya dosen Pendidikan kewarganegaraan untuk dapat menggunakan metode Role Playing, karena telah terbukti ke efektifitasanya dalam penelitian ini.

\section{DAFTAR PUSTAKA}

Adam Blatner, M.D. 2009. Role Playing In Education. (First written in 1995, and

corrected June 1, 2018)

(http://www.blatner.com/adam/pdnt bk/rlplayedu.htm)

Amm. 2018. Mencetak Generasi Emas Lewat Pendidikan karakter.

https://nasional.sindonews.com/read/124978 5/144/mencetak-generasi-emaslewat-pendidikan-karakter-
1508394296/16. Diakses pada 8 Oktober 2018 pukul 16:53

Blatner, A. (2000). Foundations of psychodrama (4th ed, revised \& expanded). New York: Springer.

Elizabeth B. Hurlock 2005. Perkembangan Anak (Diterjemahkan Meitasari Tjandrasa).Jakarta: Erlangga

Hamalik, Oemar. 2001. Perencanaan Pengajaran Berdasarkan Pendekatan Sistem. Bandung: Bumi Aksara

Hamzah B Uno 2009. Model Pembelajaran. Jakarta: Bumi Aksara

Syaiful Bahri Djamarah dan Aswan Zain 1996. Strategi Belajar Mengajar . Jakarta: Rineka Cipta 